\title{
Effects of Microwave Irradiation on the Parameters of Hydrogel Contact Lenses
}

\author{
ANTHONY CRABBE, BA, MA, PGCE and PAMELA THOMPSON, BSc, MSc, MRPS \\ Department of Design, Nottingham Trent University, Nottingham, United Kingdom
}

\begin{abstract}
Ten brands of hydrogel contact lenses were selected from five of the six British Approved Name lens classification groups to test in vitro the effects of repeated heat disinfection by means of microwave irradiation. Each lens type was tested over a number of cycles corresponding to its scheduled number of wearing days. The total diameter and back vertex power of all 80 test and 12 control lenses were measured at the end of their relevant cycling period. The back optic zone radius, center thickness, and water content were measured for 40 test and 8 control lenses. No clinically significant change was found in any of the $\mathbf{1 0}$ brands tested. Statistically significant changes were found in the back optic zone radius of the Frequency 55 group and water content of the Precision UV group. Some discoloration was noted in Ciba Visitint lenses. (Optom Vis Sci 2001;78:610-615)
\end{abstract}

Key Words: microwave, disinfection, lens materials

M icrowave irradiation has been shown to be a highly effective means of rapidly disinfecting hydrogel contact lenses. ${ }^{1-3}$ The disinfecting method appears, essentially, to be one of moist heat, ${ }^{4}$ wherein the typical practice has been to immerse each lens in a volume of 6 to $12 \mathrm{ml}$ of saline solution contained within a thermoplastic or glass vessel and then irradiate the vessel in a domestic microwave oven. Moist heat achieves three different levels of disinfection: pasteurization, complete disinfection, and sterilization. Treatment times and temperatures vary considerably according the materials being disinfected, levels of saturation, and the profile of the thermal curve used. ${ }^{5}$ Liquids held at temperatures in the range 60 to $72^{\circ} \mathrm{C}$ for periods ranging from $30 \mathrm{~s}$ to $30 \mathrm{~min}$ are termed pasteurized, which means a series of log reductions in the cell populations of certain species of challenge microorganisms. Complete disinfection, meaning a reduction to 0 colony forming units ( $\mathrm{cfu}) / \mathrm{ml}$ in all species of challenge cells, requires holding items at $100^{\circ} \mathrm{C}$ for periods of up to $5 \mathrm{~min}$. The killing of spores, to achieve sterilization, requires holding a temperature of $121^{\circ} \mathrm{C}$ for 10 to $12 \mathrm{~min}$.

Apart from Meridiano et al., ${ }^{4}$ previous investigators have not discussed whether they were using pasteurizing or complete disinfecting methods. Some investigators have consciously held to a form of pasteurization by preventing the boiling of lens solution, ${ }^{4,6}$ and others have found complete disinfection after allowing solution to visibly boil inside partially sealed cases. ${ }^{2,3}$ Regarding the testing the effects of moist microwave disinfecting on the properties and parameters of hydrogel lenses, the two prior major stud- ies have both allowed the visible boiling of lens solution during irradiation for periods of unspecified length. ${ }^{7,8}$

Most of the prior research has concentrated on the potential of microwave treatment for practice use, where batches of lenses are to be treated. The present research forms part of a larger study concerning the efficacy of a daily regimen, wherein patients completely disinfect their lenses in their own microwave ovens. A patientoperated treatment will involve quite different irradiation times from those reported in prior research. Previous researchers admit to difficulties and inaccuracies in measuring the actual solution temperatures during irradiation. ${ }^{2}$ In the present study, the temperature inside irradiated storage cases was measured over successive intervals by inserting Thermax B heat strips into the solution. It was found that in an $800 \mathrm{~W}$ oven operating at full power, the solution temperature inside a single $10-\mathrm{ml}$ thermoplastic storage case will reach $\geq 100^{\circ} \mathrm{C}$ in 10 to $12 \mathrm{~s}$ vs. the reported $120 \mathrm{~s}$ necessary when treating 20 cases in a $650 \mathrm{~W}$ oven. ${ }^{2}$ Use of heat strips also showed that in vented storage cases of the type described in earlier work, the visible boiling of saline actually occurred at temperatures in the range of 104 to $106^{\circ} \mathrm{C}$. If irradiation of a single case is then stopped at $12 \mathrm{~s}$, the solution temperature will still be higher than $72^{\circ} \mathrm{C} 3$ min later, which means that the lenses would certainly be pasteurized, but not necessarily completely disinfected. Other important considerations are as follows. Individual ovens manifest different patterns of radiation distribution, which can vary according to the age and cleanliness of the oven. ${ }^{9}$ Because the treatment times required for microwave disinfecting are relatively short, the starting temperature of the solution may also be a significant factor. 
TABLE 1.

Lenses tested, grouped according to polymer family

\begin{tabular}{|c|c|c|c|c|c|c|}
\hline Lens Type & BAN Class & FDA Class & $\begin{array}{l}\text { Replacement } \\
\text { Period, Days }\end{array}$ & $\begin{array}{l}\text { Sample } \\
\text { Number }\end{array}$ & $\begin{array}{l}\text { No. of Test } \\
\text { Cycles }\end{array}$ & $\begin{array}{l}\text { Test } \\
\text { Method }\end{array}$ \\
\hline Seequence (Bausch \& Lomb) & $1 \mathrm{a}(38)$ & 1 & 30 & 6 & 30 & A \\
\hline Vistagel $38(\mathrm{BCL})$ & $1 \mathrm{a}(38)$ & 1 & 365 & 22 & $365 / 730$ & $B \& C$ \\
\hline Surevue (Vistakon) & $1 \mathrm{~b}(55)$ & 4 & 14 & 6 & 30 & A \\
\hline Frequency 55 (Aspect) & $1 \mathrm{~b}(55)$ & 4 & 30 & 6 & 30 & A \\
\hline Review 55 (MJS) & $3 a(55)$ & 4 & 30 & 6 & 30 & A \\
\hline $\begin{array}{l}\text { Medalist } 66 \text { (Bausch \& } \\
\text { Lomb) }\end{array}$ & $4 a(66)$ & 2 & 30 & 6 & 30 & A \\
\hline Precision UV (Wesley Jessen) & $4 \mathrm{a}(70)$ & 2 & 30 & 6 & 30 & A \\
\hline Vistagel 74 (BCL) & $4 a(74)$ & 2 & 365 & 22 & $365 / 730$ & $B \& C$ \\
\hline Actifresh (Hydron UK) & $4 \mathrm{a}(74)$ & 2 & 30 & 6 & 30 & A \\
\hline Focus Visitint (Ciba Vision) & $4 b(55)$ & 4 & 30 & 6 & 30 & A \\
\hline
\end{tabular}

Instructions to users on microwave disinfecting must then allow a sufficiently large margin for variability, especially if the apparatus provided does not register the temperatures reached during irradiation. The instructions for the patient-operated system-for which the present study on lens parameters was conducted - then advised treatment times ranging between 60 and $120 \mathrm{~s}$, depending on the power rating of the oven being used (within a range of 600 to $1000 \mathrm{~W})$. These times ensured that during irradiation, the temperature of $100^{\circ} \mathrm{C}$ was reached and held for 30 to $50 \mathrm{~s}$, regardless of individual differences in ovens, and that complete disinfection was achieved. ${ }^{a}$ Proof of operation to the patient was provided by using the eventual cooling of steam produced by the boiling of solution at $100^{\circ} \mathrm{C}$ to cause a visible siphoning of solution from one chamber of the treatment vessel to another. ${ }^{10}$

In their investigations of the effects of microwave heating on lens parameters, Harris et al. ${ }^{7}$ selected a batch cycle time of $5 \mathrm{~min}$, and Quesnel et al. ${ }^{8}$ selected a time of $2 \mathrm{~min}$, based on their notions of a suitable in-office treatment cycle, as suggested by earlier batch disinfection results from Harris et al. ${ }^{3}$ Their work showed that when such irradiation cycles were repeated 90 to 200 times, there were no clinically significant alterations in the parameters of certain brands of lenses from Food and Drug Administration (FDA) groups 1 to 4 . For the purposes of testing the effects of complete microwave disinfecting on further lens types, a treatment cycle may then be characterized as follows. A microwave treatment cycle for complete disinfection involves taking lenses and solution at room temperature, raising their temperature by irradiation to 100 to $105^{\circ} \mathrm{C}$, holding it there for a period ranging from a few seconds to a few minutes, and then allowing them to cool back to room temperature. Differences in treatment time reflect the wide variations in equipment to be used and lens numbers treated.

\footnotetext{
${ }^{a}$ In unpublished microbiological testing of lens pairs challenged with Acanthamoeba castellanii, Candida albicans, Pseudomonas aeruginosa, and Staphylococcus aureus, a 60 -s microwave irradiation in a $750 \mathrm{~W}$ oven, followed by a 10 -min cooling, resulted in reduction from $104 \mathrm{cfu} / \mathrm{ml}$ to $0 \mathrm{cfu} / \mathrm{ml}$ for all 40 samples tested. In a test following Food and Drug Administration protocols for proving of contact lens heat disinfectors, 10 lens pairs challenged with Enterococcus faecalis were irradiated at medium power in an $750 \mathrm{~W}$ oven for $120 \mathrm{~s}$, resulting in a reduction from $107 \mathrm{cfu} / \mathrm{ml}$ to $0 \mathrm{cfu} / \mathrm{ml}$ in all 20 samples (Cartledge T, Crabbe A. Report to Medical Devices Agency UK: the efficacy of a microwave disinfection system for soft contact lenses. Departments of Life Sciences \& Design, Nottingham Trent University, 1996).
}

In the present study, two groups of researchers used three methods of batch irradiating test lenses for cycle periods ranging between 120 and $150 \mathrm{~s}$. The methods were devised to facilitate testing of the full spectrum of lens types most commonly used by patients, which involved irradiating large numbers of lenses up to a maximum of 7302 -min cycles. The criteria for lens selection were that lenses should be taken from each main polymer class, replacement frequency type, and with a variety of different prescription values. These criteria produced an assortment of 92 lenses for testing, comprising a test group of 80 lenses and a control group of 12 lenses.

\section{METHODS}

\section{Lens Materials}

Previous researchers such as Harris et al. ${ }^{7}$ and Quesnel et al. ${ }^{8}$ have used lenses with a single common prescription and with brands selected according to the U.S. FDA system of lens classification. The present study investigated an entirely random group of different prescriptions and lens thickness, ranging in back vertex power from -13.75 to $+12.00 \mathrm{D}$, to reflect the kind of diversity encountered in practice. The British Approved Name (BAN) system of lens classification was preferred to the FDA system, because BAN classifies lenses by polymer families, rather than water content and ionic nature. BAN, therefore, allows for better generalization about the mechanical effects of heating on lenses belonging to specific polymer families. The one limitation of choosing the BAN system was that there are no commonly used lens brands in

\section{TABLE 2.}

Clinically significant changes selected for lens parameters and SEM for equipment used

\begin{tabular}{lccc}
\hline \multicolumn{1}{c}{ Lens Parameter } & $\begin{array}{c}\text { Significant } \\
\text { Change }\end{array}$ & $\begin{array}{c}\text { SEM Test } \\
\text { A }\end{array}$ & $\begin{array}{c}\text { SEM Test } \\
\text { B and C }\end{array}$ \\
\hline Total diameter $(\mathrm{mm})$ & 0.25 & 0.12 & 0.15 \\
Back vertex power $(\mathrm{D})$ & 0.25 & 0.09 & 0.12 \\
Back optic zone radius $(\mathrm{mm})$ & 0.30 & 0.06 & - \\
Center thickness $(\mu \mathrm{m})$ & 10.0 & 8.9 & - \\
Water content $(\%)$ & 5.0 & 0.5 & - \\
\hline
\end{tabular}




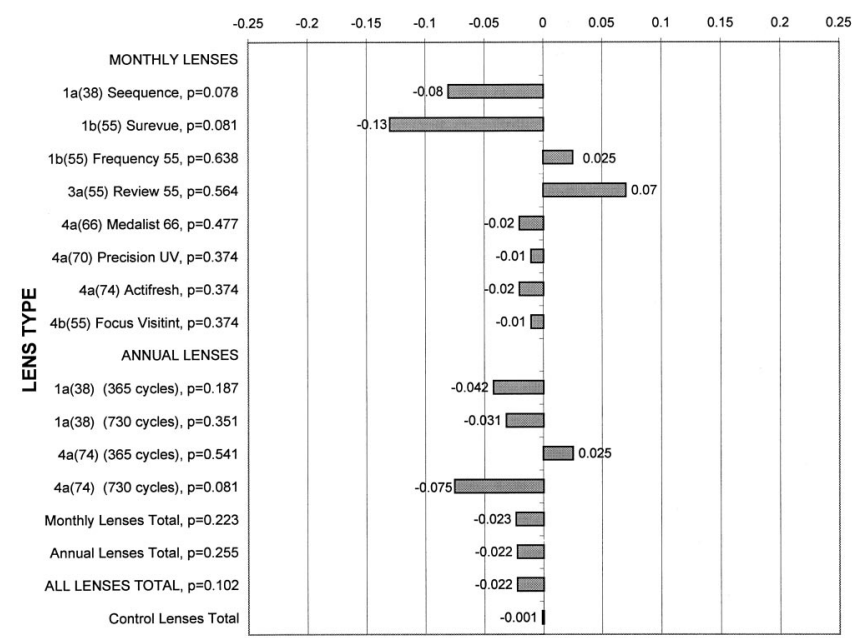

\section{FIGURE 1.}

Mean change in total diameter $(\mathrm{mm})$. Clinically significant change $=0.25$ $\mathrm{mm}$.

the $3 \mathrm{~b}$ category that could be included under the protocols of the present study. The lenses selected were as shown in Table 1.

\section{Irradiation of Lenses}

In conformity with the characterization of a treatment cycle for complete disinfection given above, test methods $\mathrm{A}$ to $\mathrm{C}$ all raised the temperature of test lenses in saline from room temperature to boiling by microwave irradiation and then cooled them back to their start temperature. In all three methods, lenses were exposed to at least $45 \mathrm{~s}$ of irradiation at boiling temperature. In all three test methods, measures were taken to ensure that at the start of each treatment cycle, lenses were fully immersed in isotonic saline at room temperature.

The first irradiation method A was devised to test 48 monthly replacement lenses, 40 test and 8 control, for 30 cycles. The testing work was then carried out by the Eurolens team, based in University of Manchester Institute of Science and Technology, U.K. ${ }^{b}$ For the test group, the method was to place a single lens in $7 \mathrm{ml}$ of isotonic saline solution contained in one of 40 barrel storage cases. The cases were specially manufactured using polycarbonate for the purpose of microwave treatment, which according to the manufacturer's Materials and Safety Data Sheet, can withstand temperatures of up to $150^{\circ} \mathrm{C}$ without degradation. The storage cases were split into two batches of 20 cases. Each batch of 20 cases was then loaded into a domestic $750 \mathrm{~W}$ microwave oven with a turntable and irradiated for approximately $100 s$ until the cases showed visible and audible signs of boiling. Upon boiling, the oven was set for a further $45 \mathrm{~s}$ of irradiation, giving a total treatment time of $150 \mathrm{~s}$. The cycle was completed by allowing the lenses to stand and cool to room temperature. The cooling took another $15 \mathrm{~min}$, during which time the second batch was irradiated. When the cases of one batch had cooled, the solution was discarded and replaced with 7

\footnotetext{
${ }^{\mathrm{b}}$ Maldonado-Codina C, Morgan PB, Goodwin M, Efron N. Unpublished report: an investigation of the effects of a microwave disinfection system on the parameters of eight different soft contact lens types. European Center For Contact Lens Research, Department of Optometry \& Vision Sciences, UMIST, Manchester, UK, 1997.
}

$\mathrm{ml}$ of fresh saline before the lenses were re-cycled. The control group lenses were placed into eight more storage cases and were not irradiated.

The second method B was devised to test 42 annual replacement lenses for 365 cycles. The test group was composed of $2074 \%$ lenses and $2038 \%$ lenses; the control group was composed of four lenses, two $74 \%$ and two $38 \%$. Compartmentalized polypropylene trays were used to hold the lenses; each tray was divided into 12 compartments of 20-ml capacity. One test lens was placed in each compartment, and each lens was immersed in $2 \mathrm{ml}$ of isotonic saline. The trays were stacked one on top of the other, and the whole assembly was capped by a tray filled only with $80 \mathrm{ml}$ of tap water to increase the thermal load to $140 \mathrm{ml}$, which prevented significant evaporation of saline during irradiation. The assembly was then loaded into a Toshiba $650 \mathrm{~W}$ oven with a turntable and irradiated at full power for $2 \mathrm{~min}$. At the end of each cycle, approximately $0.3 \mathrm{ml}$ of solution had evaporated from each compartment, and the saline concentration of the remaining $1.7 \mathrm{ml}$ of solution had risen accordingly. The mechanics of handling 40 test lenses over 365 cycles made it impracticable to replace each lens in fresh saline at the start of each irradiation cycle, as was done in test method A. Accordingly, in method B, the solution volume and concentration were restored to their isotonic start values by addition of $0.3 \mathrm{ml}$ of purified water British Pharmacopoeia (B.P.) through a pipette. Four control lenses were put into $2 \mathrm{ml}$ of saline in the compartments of another tray, which was not irradiated.

The third method $\mathrm{C}$ was devised to overcome difficulties encountered in method B above, which led to occasional loss or damage to lenses because of lenses sticking to surfaces within the compartments. Method $\mathrm{C}$ was used to test 22 of the annual replacement lenses used in method B for a further 360 cycles. The test group was composed of $1074 \%$ lenses and eight $38 \%$ lenses; the control group comprised four lenses, two $74 \%$ and two $38 \%$. In method C, a thermoplastic microwave container with a capacity of 1.5 liters, was filled with $1100 \mathrm{ml}$ of isotonic saline solution. Twenty $25-\mathrm{mm}$ holes were drilled into the lid of the container. Through these holes were inserted the lens holder assemblies of the same storage cases described in method A. Because the caps of the lens holders were larger than the holes, the lenses could be suspended under the container lid, so that when the lid was placed on top of the base, all the lens holders were fully immersed within the $1100 \mathrm{ml}$ of saline. A second, identical, container base was filled with 1 liter of saline at room temperature to use as a plunge bath for cooling the lenses after each heating cycle.

At the start of each irradiation cycle, the saline-filled container, without lenses inserted, was brought to boiling in the microwave oven. Thereupon, the loaded lens holders, suspended under the lid, were placed immediately into the hot solution, and the whole assembly was brought back to a boil. As soon as it was boiling, the first cycle was set to $2 \mathrm{~min}$. After irradiation, the lid was immediately removed and replaced with a normal lid that helped maintain the temperature of the hot saline. The lenses were then plunged into the container containing saline at room temperature and soaked for $10 \mathrm{~s}$.

Having been plunge-cooled this way, the lenses were immediately returned to the hot solution, and the next irradiation cycle started. The total cycle time turned out to be approximately $2 \mathrm{~min}$ and $20 s$-although frequent adjustments were made to guarantee 


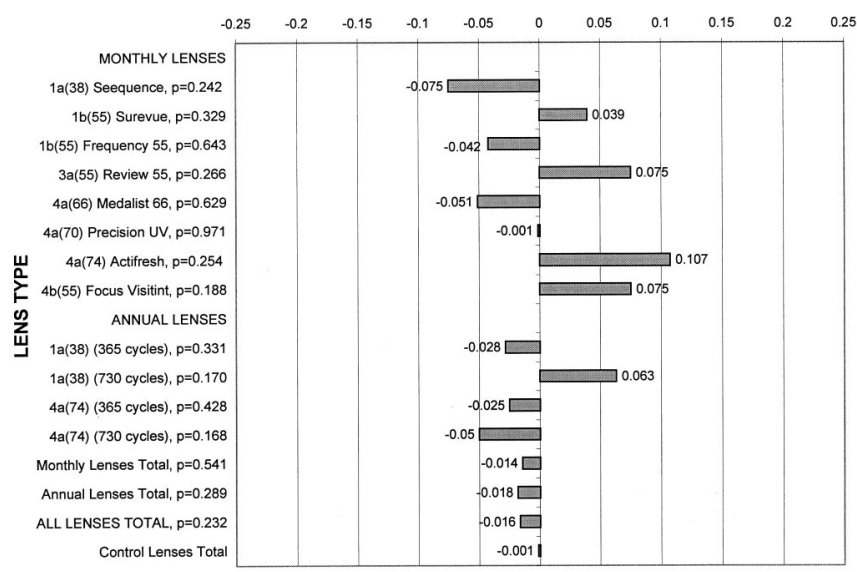

FIGURE 2.

Mean change in back vertex power (D). Clinically significant change $=$ 0.25 D.

that the total boiling time was 2 min per cycle. After each cycle, approximately $10 \mathrm{ml}$ of solution had evaporated, and as in method $\mathrm{B}$, the practical method of restoring the solution to isotonic values at the beginning of each cycle was to add $10 \mathrm{ml}$ of fresh purified water B.P. To speed the heating and hold a much larger thermal load at $100^{\circ} \mathrm{C}$, a new Panasonic $800 \mathrm{~W}$ oven with a turntable was used for this method $\mathrm{C}$. The four control lenses were left standing in two storage cases, each containing $7 \mathrm{ml}$ of saline, and were not irradiated.

\section{Lens Measurement}

After consultation with both optometrists and contact lens manufacturers, it was decided in method A, which was used on monthly replacement lenses, to test the parameters selected by Harris et al. ${ }^{7}$ and Quesnel et al. ${ }^{8}$ These were total diameter, back vertex power (BVP), back optic zone radius (BOZR), water content, and center thickness. For methods B and C, measurement of the lathe-cut annual lenses was carried out by the manufacturers after their standard Communité Européen quality assessment procedures. In these procedures, total diameter and BVP are measured to $\pm 0.25 \mathrm{~mm}$ and $\pm 0.25 \mathrm{D}$ before labeling, rather than to \pm 0.30 $\mathrm{mm}$ and $\pm 0.36 \mathrm{D}$, which is considered clinically significant in "The CCLRU Good Lens Guide" ${ }^{11}$ cited by both Harris et al. and Quesnel et al.

All lenses were randomized and then measured masked by examiners not involved in the irradiation treatment. Lenses were first measured in fresh saline before irradiation and subsequently measured in fresh saline by the same examiners within $4 \mathrm{~h}$ of the final treatment cycle. For method A, the following measuring equipment and techniques were used (Table 2). Total diameter and BOZR were measured at $20^{\circ} \mathrm{C}$ in $0.9 \%$ physiological saline using the Optimec JCF with the TC20 saline circulating system. BVP was measured using a Topcon Lm-P6 Lensmeter in air at room temperature. Center thickness was measured using a Rehder ET-1 electronic thickness gauge, and water content was measured using an Atago CL-1 hand held refractometer at room temperature. The Atago refractometer was not able to measure the water content of Ciba Visitint lenses, a problem that was attributed by the Eurolens team to these lenses having a variable refractive index. For methods $\mathrm{B}$ and $\mathrm{C}$, the lens manufacturers were asked to use the same measuring equipment that they used in their quality control. For total diameter, this was a Moore \& Wright 961 MF calibrated micrometer in air at room temperature, and for BVP, a Nikon PL1 focimeter in air at room temperature.

\section{Data Analysis}

Data from all three tests were recorded and analyzed using Microsoft Excel 97. Initial and final measurements were analyzed statistically by means of a two-tailed paired t-test, with a hypothesized difference $=0$. The baseline provided by the control lenses then gave a point of reference about the range of error arising in the measuring procedures. The level of statistical significance was set at $\alpha=0.05$.

\section{RESULTS}

The solution temperature in vessels used for the tests was measured using calibrated temperature strips (Thermax Range B, accuracy $\pm 1^{\circ} \mathrm{C}$ ) inserted into the solution during irradiation. The average temperature was $105^{\circ} \mathrm{C}$ for the storage cases used in method $\mathrm{A}, 104^{\circ} \mathrm{C}$ for the trays in method $\mathrm{B}$, and $102^{\circ} \mathrm{C}$ for the vessel in method C. In method A, some lenses were initially found to be sticking to the lens holders, and one Frequency 55 lens was lost due to tearing during removal. In method B, two Vistagel 38\% lenses were lost due to the tendency of the unrestrained lenses to move about in the turbulent boiling of the solution. At the end of testing, all five Focus Visitint lenses were found to be slightly discoloured, with a brownish hue. The results for each parameter tested are presented in Figs. 1 to 5. Clinically significant changes in individual lenses are listed in Table 3.

TABLE 3.

Individual test lenses showing clinically significant change \pm in parameters

\begin{tabular}{lcccccc}
\hline \multicolumn{1}{c}{ Lens Type } & Number & $\mathrm{TD}^{a}(\mathrm{~mm})$ & $\mathrm{BVP}(\mathrm{D})$ & $\mathrm{BOZR}(\mathrm{mm})$ & $\mathrm{CT}(\mu \mathrm{m})$ & WC $(\%)$ \\
\hline Seequence & 1 & - & - & - & - & 6 \\
Surevue & 1 & - & - & 0.31 & - & - \\
Vistagel 74 (365 cycles) & 1 & -0.30 & - & - & - & - \\
Actifresh & 1 & 0.50 & - & - & - & - \\
Seequence (control) & 1 & - & - & - & - & - \\
\hline
\end{tabular}

a TD, total diameter; BVP, back vertex power; BOZR, back optic zone radius; CT, center thickness; WC, water content. 


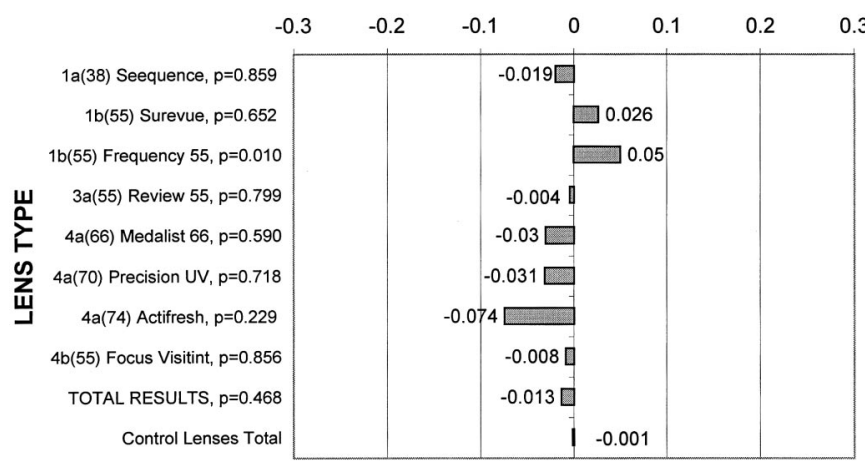

FIGURE 3.

Mean change in back optic zone radius $(\mathrm{mm})$. Clinically significant change $=0.30 \mathrm{~mm}$.

\begin{tabular}{|c|c|c|c|}
\hline & -5 & 0 & 5 \\
\hline $1 a(38)$ Seequence, $p=0.212$ & & $\square 0.533$ & \\
\hline $1 b(55)$ Surevue, $p=0.650$ & $-0.533 \square$ & & \\
\hline $1 \mathrm{~b}(55)$ Frequency $55, \mathrm{p}=0.697$ & & $\square 0.917$ & \\
\hline 3a(55) Review $55, p=0.744$ & & 0.4 & \\
\hline 4a(66) Medalist $66, p=0.881$ & -0.133 & & \\
\hline $4 a(70)$ Precision $U V, p=0.281$ & & $\square 0.867$ & \\
\hline 4a(74) Actifresh, $p=0.543$ & $-0.8 \square$ & & \\
\hline $4 \mathrm{~b}(55)$ Focus Visitint, $\mathrm{p}=0.546$ & $-1.133 \square$ & & \\
\hline TOTAL RESULTS, $p=0.983$ & -0.008 & & \\
\hline Control Lenses Total & -0.001 & & \\
\hline
\end{tabular}

\section{FIGURE 4.}

Mean change in center thickness $(\mu \mathrm{m})$. Clinically significant change $=10$ $\mu \mathrm{m}$.

\section{DISCUSSION}

No clinically significant mean changes were found in the parameters of any lens type tested. Statistically significant changes were found in BOZR in Frequency 55 and water content in Precision UV. In common with previous research, ${ }^{7,8}$ the present work does not reveal predictable trends or patterns in the parameter shifts of lenses belonging to different FDA or BAN categories. Although there have been reservations dating back to the 1980s concerning the suitability of heat disinfection for higher water content lenses, ${ }^{12}$ the changes in parameters of high water content lenses appears little different to mid and low water content lenses. Looking at the $4 \mathrm{a}$ and $4 \mathrm{~b}$ lenses, the changes in total diameter and water content were slightly less than for groups 1 a to 3 a and slightly greater in BOZR and center thickness. Prior research ${ }^{7,8}$ has found small but statistically significant increases in water content for low and mid water content lenses. In the present testing, a small but statistically significant increase was also found in water content for one lens brand, Precision UV, a high water content lens. However, greater changes were found in water content for Medalist 66 and Review 55 , and these were reductions in water content. The very small increase in water content for all test lenses does not provide much support for the hypothesis that microwave treatment necessarily increases the water content of hydrogel lenses.

Figs. 1 to 5 show that the mean change in each parameter of the lens brands tested was considerably less than the corresponding limit of clinical significance. As found in prior testing ${ }^{7,8}$, most

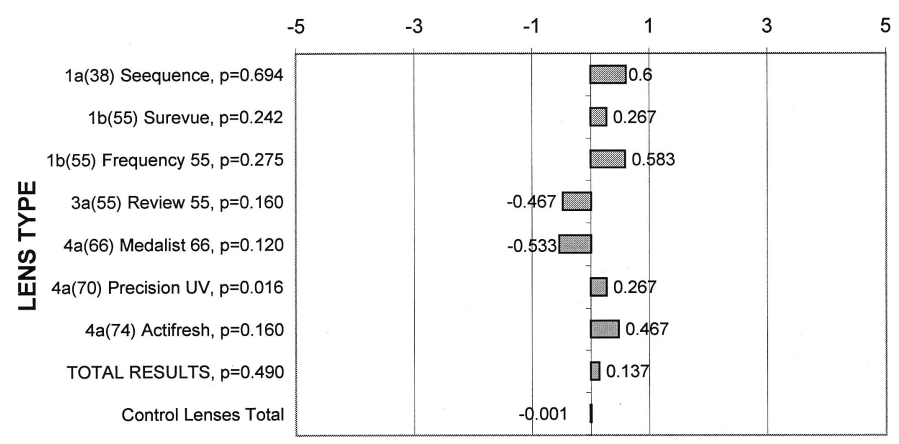

\section{FIGURE 5.}

Mean change in water content (\%). Clinically significant change $=5 \%$.

parameter changes were very close to the SEM limits for the measuring equipment used. In the testing by Harris et al., ${ }^{7}$ which involved treating the lenses for cycle times of $5 \mathrm{~min}$, some of these small changes were statistically significant in as many as four of the five parameters tested for certain lens brands. In the work of Quesnel et al., ${ }^{8}$ which involved 2 min cycles, only the changes in water content were found to be statistically significant. In the present testing, the incidence of statistically significant parameter changes was lower again, with the only such changes found being in water content for Precision UV and BOZR for Frequency 55. The clinically significant changes found in four individual lenses listed in Table 3 do not appear to be statistically significant. The clinically significant change found in BOZR for one Seequence control lens further suggests that these findings could have resulted from handling and measuring errors rather than from heating effects. The present findings appear to support the views of prior researchers that microwave heating of hydrogel lenses may lead to small, statistically significant changes in some parameters of some lenses, but the changes are well within the limits of clinical acceptability.

In view of the prevalent manufacturing practice of heat sterilizing hydrogel lenses at $120^{\circ} \mathrm{C}$ before sale, it was surprising to discover some discoloration in the five Visitint lenses. Inquiries to the manufacturer revealed that they specifically contraindicate the use of heat disinfection for this particular lens brand, which uses a proprietary tinting agent. Because the measurements of Visitint lenses do not reveal unusual alterations in any parameter of the lenses, it is likely that heating by irradiation effects changes in the chemistry of this tinting agent rather than in the lens polymer.

\section{CONCLUSION}

In common with previous research, the present testing shows that heating of unworn hydrogel lenses by microwave irradiation does not cause clinically significant mean changes in the lens parameters of 10 previously untested lens brands, selected from 5 of 6 BAN lens polymer groups. Clinically significant changes in a single parameter were found in four of the 80 test lenses and in one of the 12 control lenses. Of the small changes found in all lens parameters, only mean changes in one parameter each of two lens brands were found to be statistically significant. Some discoloration was noted in one of the six tinted lens brands used. Although this promises well for the continuing investigation of microwave treatment of hydrogel lenses for patient use, the scope of the 
present investigation has been limited to observing the effects in vitro on the clinical parameters of hydrogel lenses. Further investigation is needed to determine the significance of other clinical effects when lenses are treated by patients in vivo.

\section{ACKNOWLEDGMENTS}

We thank Eurolens Research, UMIST, UK, Peter Carr, Belgravia Contact Lens Laboratory, Nottingham, UK, and John Frankland, Polymeric Sciences, Hants, UK.

Received December 16, 1999; revision received March 21, 2001.

\section{REFERENCES}

1. Rohrer MD, Terry MA, Bulard RA, Graves DC, Taylor EM. Microwave sterilization of hydrophilic contact lenses. Am J Ophthalmol 1986;101:49-57.

2. Harris MG, Kirby JE, Tornatore CW, Wrightnour JA. Microwave disinfection of soft contact lenses. Optom Vis Sci 1989;66:82-6.

3. Harris MG, Rechberger J, Grant T, Holden BA. In-office microwave disinfection of soft contact lenses. Optom Vis Sci 1990;67:129-32.

4. Meridiano MD, Marqués S, Lluch M, Gonzàles M, Saona C. Domestic microwave oven in contact lens disinfection. Contact Lens J 1990;18:241-6.

5. Russell AD, Hugo WB, Ayliffe GAJ. Principles and Practice of Dis- infection, Preservation and Sterilization, 2nd ed. Oxford: Blackwell, 1992;483-511.

6. Hatch SW, Paramore JE. Effects of microwave disinfection on hydrogel lenses. ICLC 1990;17:264-70.

7. Harris MG, Gan CM, Grant T, Lycho T, Holden BA. Microwave irradiation and soft contact lens parameters. Optom Vis Sci 1993;70: 843-8.

8. Quesnel N, Simonet P, Giasson C. Stability of Crofilcron and Polymacon (clear and tinted) contact lenses after microwave irradiation. J BCLA 1996;19:49-54.

9. Metaxas AC, Meredith RJ. Industrial Microwave Heating. IEEE Power Engineering, Series 4. London: Peter Peregrinus, 1983; 279-303.

10. Hirji N. A novel device for disinfecting hydrogel contact lenses. Optician 1997;214:38-9.

11. Lahood D, Holden BA, Zabkiewiczk K. The CCLRU Good Lens Guide. Am J Optom Physiol Optics 1985;62(Suppl):112.

12. Lubert GP, Caplan L. Comparing thermal and chemical disinfection systems for the etafilcon A 58\% water content contact lens. Am J Optom Physiol Opt 1984;61:683-8.

Anthony Crabbe Department of Design Nottingham Trent University Burton Street, Nottingham NG5 $2 \mathrm{HA}$

United Kingdom e-mail:anthony.crabbe@ntu.ac.uk 